\section{DNA barcoding for the verifica- tion of supplier's compliance in the seafood chain: How the lab can support companies in ensuring traceability}

\author{
Lara Tinacci, ${ }^{1}$ Alessandra Guidi, ${ }^{1}$ \\ Andrea Toto ${ }^{1}$ Lisa Guardone, ${ }^{1}$ \\ Alice Giusti, ${ }^{1}$ Priscilla D'Amico, ${ }^{2}$ \\ Andrea Armani ${ }^{1}$ \\ ${ }^{1}$ FishLab, Department of Veterinary \\ Sciences, University of Pisa; ${ }^{2}$ Seafood \\ quality manager, Florence, Italy
}

\section{Abstract \\ Food Business Operators (FBOs) rely} on laboratory analysis to ensure seafood traceability. DNA barcoding and Forensically Informative Nucleotide Sequencing may represent a support within self-checking programs finalized to suppliers' qualification and products identity certification. The present study aimed at verifying the usefulness of a decisional procedure (decision tree) set up at the FishLab (Department of Veterinary Sciences, University of Pisa, Italy) for seafood species identification by DNA analysis, to cope with FBOs' needs. The decision tree was applied to the analysis of 182 seafood (fish and molluscs) products, conferred to the FishLab by different FBOs between 2014 and 2015 as result of their self-checking activities. The analysis relied on a standard COI gene fragment eventually integrated by the analysis of alternative or supportive molecular targets (cytb and $16 \mathrm{~S}$ $r R N A$ ). It also included a mini-DNA barcoding approach for processed products. Overall, $96.2 \%$ of the samples were unambiguously identified at species level using the elective target alone $(92.4 \%)$ or a multitarget approach (3.8\%). The lack of species identification (3.8\%) was attributable to the absence of reference sequences or to the low resolution of the molecular targets. Nonetheless, all the molecular results were deemed adequate to evaluate the sample's compliance to the label information. Noncompliances were highlighted in $18.1 \%$ of the products. The protocol was proven as an effective supportive tool for the seafood identity verification within the supply chain self-checking activities. In addition, a considerable fraud rate was confirmed and the species most frequently involved in substitution were pointed out.

\section{Introduction}

Economically Motivated Adulterations (EMA) of food, or more simply frauds, are a growing phenomenon due to the relevant gains that can be achieved by substituting high quality with less valuable products (Spink et al., 2016). In the fishery sector frauds are favored by the high complexity of the globalized supply chain, which exposes seafood trade to safety and quality challenges (http://oceana.org/sites/default/ files/reports/Seafood_Traceability_Report FINAL). At the European level, the Regulation (EU) n. 1379/2013 establishes some mandatory information (commercial and scientific name, production method, origin, category of fishing gear used for the catching) that must accompany seafood all along the supply chain (D'Amico et al., 2016). Thus, ensuring seafood traceability represents a priority of Food Business Operators (FBOs) that are responsible for all the information provided to the downstream operators or to the consumers. However, concerns about the effective maintenance of seafood traceability arise considering that the seafood supply chain operating at national and international level usually involves many intermediaries between the primary production (catch or aquaculture) and the final delivering (Thorpe and Benneth, 2004). Moreover, the lack of an international standardized labeling and seafood naming system, the inappropriate training of fishery operators and the removal of morphological features during processing affect the correct identification of seafood commodities (Cawthorn et al., 2015; Leal et al., 2015). In addition, the seafood industry is the second food sector most exposed to adulteration and the replacement of low-value seafood species for greater value species (aliud pro alio fraud), represents a frequent illegal practice (D'amico et al., 2016). Fraudulent behaviors expose consumers not only to commercial but also to health issues and undermine stock conservation efforts (Stawitz et al., 2016; Armani et al., 2015a; Warner et al., 2013). By the years, many initiatives have been proposed to provide FBOs with guidelines to comply with the mandatory EU traceability (Aung and Chang, 2014). These were furtherly implemented by the ISO $12875: 2011$ and ISO $12877: 2011$ on the information to be recorded for captured and farmed finfish distribution chains, respectively (https://www.iso.org/obp/ui/\#iso: std:iso:12875:ed-1:v1:en; and https://www. iso.org/obp/ui/\#iso:std:iso:12877:ed1:v1:en). However, these standards do not specify the analytical instruments for the acquisition and the management of trace-
Correspondence: Andrea Armani, FishLab, Department of Veterinary Sciences, University of Pisa, Via delle Piagge 2, 56124, Pisa, Italy.

E-mail: andrea.armani@unipi.it

Key words: Seafood, Species identification, DNA, Supply chain self-check, Traceability, Frauds.

Contributions: the authors contributed equally

Conflict of interest: the authors declare no potential conflict of interest.

Funding: none.

Received for publication: 11 July 2017.

Revision received: 16 March 2018.

Accepted for publication: 21 March 2018.

This work is licensed under a Creative Commons Attribution-NonCommercial 4.0 International License (CC BY-NC 4.0).

CCopyright L. Tinacci et al., 2018

Licensee PAGEPress, Italy

Italian Journal of Food Safety 2018; 7:6894

doi:10.4081/ijfs.2018.6894

ability data, delegating to FBOs the selection of the most performant tool according to the implemented traceability plan (Tamm et al., 2016). Therefore, seafood traceability procedures applied in the supply chain consist of record-keeping methodologies represented by simple, paper-based records or by complex electronic data systems and radio frequency identification (RFID) (Aung and Chang, 2014). Moreover FBOs have begun to adopt specific supplier's monitoring systems which are usually based on customer complaints, direct controls (such as visual inspections, control of transport temperatures) and laboratory analysis (Barach, 2016, Aung and Chang, 2014).

Analytical tools may offer a significant support to the fishery sector companies, especially those dealing with import/export and large distribution, for the verification of the accompanying documents. Laboratory activities are especially intended to checkup incoming goods at the time of acceptance as well as monitor suppliers' reliability (Barach, 2016).

DNA-based methods, particularly DNA barcoding and Forensically Informative Nucleotide Sequencing (FINS) are nowadays the most routinely utilized since they fully address the requirements stated by rules and can be applied throughout the whole supply chain (Handy et al., 2011; Aung and Chang, 2014). Therefore, they can be used to support companies' self- 
checking program for goods' verification. However, to cope with the huge gamma of seafood products currently traded worldwide and the need to quickly respond to FBOs, a suitable workflow protocol is required (Griffiths et al., 2014).

At the FishLab of the Department of Veterinary Sciences (University of Pisa) an identification protocol based on DNA analysis, operating like a systematic decision-making tool, generally known as decision tree analysis, was developed to sort out the most appropriate lab pathways in the light of the features of the samples to be analyzed. This study aimed at checking the usefulness of the aforesaid protocol to verify the identity of seafood sent to our lab by FBOs during 2014 and 2015 within the selfchecking programs of companies. The ability to respond to the needs of FBOs is discussed in the light of the results obtained.

\section{Materials and Methods}

\section{Reception of the samples}

A total of 182 tissue samples from fishery products were sent to our lab from 2014 to 2015 by distinct Italian wholesaler distributors (WD) and seafood retail delivery platforms (RP): 133 were sent to the laboratory from WD and the remaining 49 from RP. All the samples were collected in the framework of self-check programs. The samples included 162 fish (159 fresh and 3 salted products), 16 fresh cephalopods and 4 frozen and precooked mollusk bivalves, that were conferred to our laboratory accompanied by the trade name and the scientific name recovered from the tracking documents (Supplementary Table 1). Each sample was registered and submitted to the decision tree analysis graphically described in Figure 1. Then it was analyzed following a four steps identification protocol.

\section{Application of the four-steps proto- col for the samples analysis}

\section{DNA extraction and quality assessment}

Total DNA extraction was performed from $100 \mathrm{mg}$ of tissue using the protocol proposed by Armani et al. (2014). DNA concentration and purity were assessed with Nanodrop ND-1000 spectrophotometer (NanoDrop Technologies, Wilmington, DE, US) by two subsequent measurements of the absorbance value at $260 \mathrm{~nm}$ and the calculation of the absorbance ratios A260/A280 and A260/A230. All the DNA samples extracted from processed products were submitted to gel electrophoresis and classified according to their degree of fragmentation as described in Armani et al. (2017).

\section{DNA amplification}

The selection of the molecular target follows the decision tree reported in Figure 1. The Cytochrome $\mathrm{C}$ oxidase subunit I (COI) gene was selected as the first choice target except for tuna products for which the $c y t b$ gene was chosen as elective target. Two primer pairs proposed by Folmer et al. (1994) and Handy et al. (2011) were selected for obtaining a COI fragment of 655-658 bp Full Length Barcode (FLB) from mollusks and fish DNA, respectively. The primers designed by Sevilla et al. (2009) were used for the amplification of the entire $c y t b$ gene (1140 bp) or for a 854 bp fragment. In the presence of medium-highly DNA fragmentation (fragment $<500 \mathrm{bp}$ ) two primer pairs were used for the amplification of a shorter DNA targets: one proposed by Armani et al. (2015b) for obtaining a 139 bp COI fragment and one designed by Kocher et al. (1989), for the amplification of a $464 \mathrm{bp}$ cytb fragment. Each sample was initially analyzed using one target gene (long or short fragment). Alternative targets such as the entire $c y t b$ target and/or a fragment of $\sim 550 \mathrm{bp}$ of the $16 S$ rRNA obtained by the primer pair
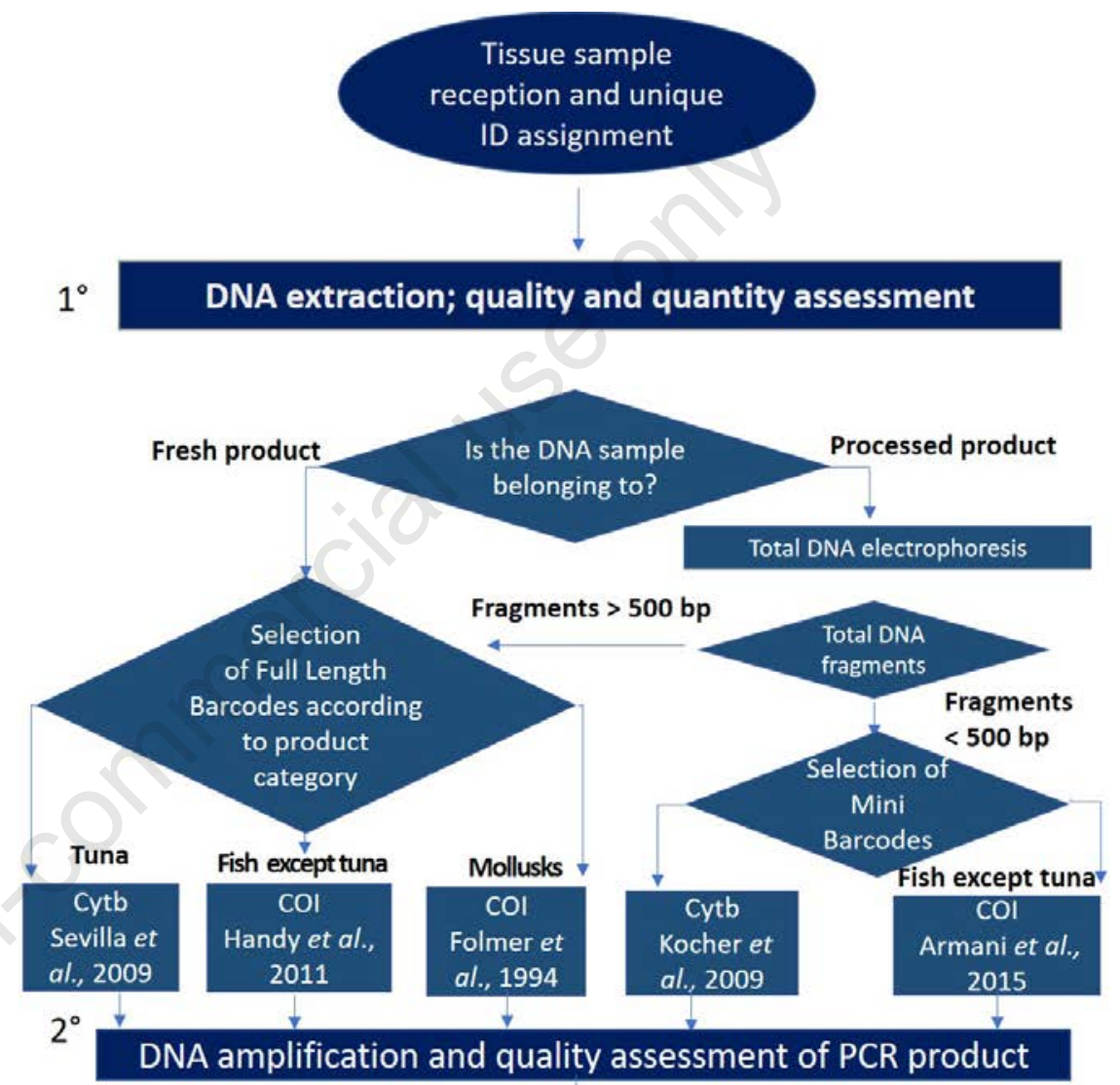

\section{DNA sequencing (out sourced)}
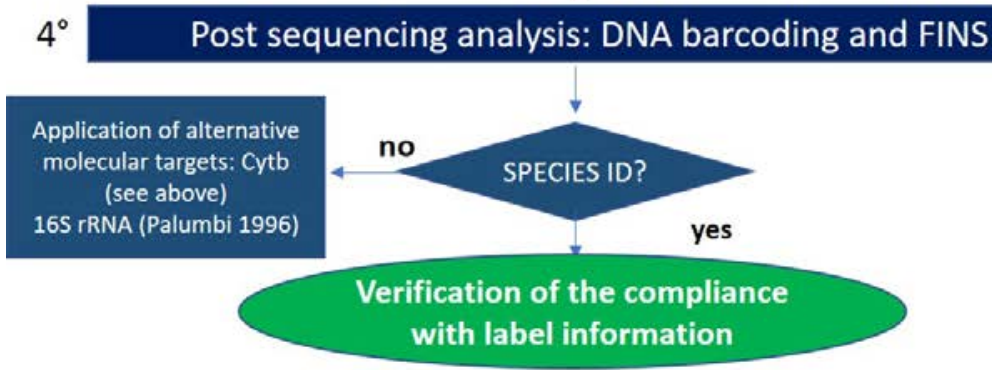

Figure 1. Decision tree analysis developed by FishLab and used in this study to select the protocol of analysis. 
designed by Palumbi (1996) were further amplified if the post sequencing analysis of the elective target alone (COI) did not allow species identification (Figure 1). The PCR amplification and PCR products purification were set according to the protocol described in Armani et al. (2017) except for the amplification of DNA samples belonging to bivalves for which the standard Taq was substituted with a 5 '-exonuclease deficient Taq polymerase KlenTaq LA (DNA Polymerase technology, Inc, USA).

\section{DNA sequencing and evaluation of the sequencing products quality}

DNA sequencing was carried out by GATC Biotech AG, European Custom Sequencing Centre (Cologne Germany). Forward and reverse sequences were aligned with Clustal W program as described in Armani et al., (2017).

\section{Post sequencing analysis}

Final sequences were queried against the reference sequences available on GenBank and BOLD databases by the means of Basic Local Analysis Search Tool (BLAST) (https://blast.ncbi.nlm.nih.gov/ Blast.cgi) and Identification System (ID's) (Ratnasingham and Hebert, 2007). The Barcoding identity score cut-off and the parameters of the Neighbour Joining analysis used for species identification were set as reported in Armani et al. (2017). The results obtained by the analysis of the molecular target were compared to the commercial designation and scientific name provided by the different suppliers. The samples were declared non-compliant if the commercial designation provided by the Ministry of agricultural food and forestry policies (https:/www.politicheagricole.it/ flex/cm/pages/ServeBLOB.php/L/IT/IDPag ina/156) for the molecularly identified species, did not match the declared one.

\section{Results}

\section{Samples composition}

The self-checking programs of supplier were plausibly driven by the European consumer's buying preferences (EUMOFA, 2015: https://www.eumfa.eu/documents/ 20178/66003/EN_The+EU+fish+market_E $\mathrm{d}+2015$.pdf/4cbd01f2-cd49-4bd1-adae$8 \mathrm{dbb} 773 \mathrm{~d} 8519)$ and during the two-year survey the sampling was mainly focused on fish $(88 \%)$, followed by mollusks $(12 \%)$, of which 10\% cephalopods (squid, cuttlefish and octopus) and $2 \%$ bivalves (Figure 2).

Among the fish category, samples declared as cod and hake were the most frequently conferred to our lab. Particularly, the Atlantic cod represented $85.7 \%(48 / 56)$ of the Gadiformes analyzed. Among these products, 3 were salted ( $2 / 3$ labelled as baccalà). Tunas was the second most sampled group $(23 \%, 42 / 182)$ and consisted almost entirely of Yellowfin Tuna and few Bigeye tuna products. Groupers, leaded by Goldblotch grouper, and flatfish, mainly represented by European plaice and Spiny turbot, were the third and fourth fish most collected groups. Less frequent self-checking sampling were addressed to goatfish, salmon, trout and clupeids, and sporadically to a variety of different species (redfish, gurnards, Nile perch, John dory, Amberjack, sharks and porgies) (Supplementary Table 1; Figure 2). About mollusks, the cephalopod products were constituted by longfin and shortfin squid, octopus and cuttlefish. Finally, the 4 bivalves consisted of Chilean mussel, Blue mussel and one veined clam product (Supplementary Table 1).

\section{DNA extraction and amplification}

The spectrophotometric analysis confirmed high yield and quality (A260/A280 and A260/A230 ratio >2.0) for all the samples analyzed except for the total DNA obtained from bivalves for which low A260/230 ratio $(<1.5)$ was observed. For all the DNA samples the elective target was successfully obtained at the first amplification, or eventually amplified using one supportive molecular target, providing a final amplification and sequencing rate of $100 \%$.

\section{DNA Sequencing and post sequenc- ing analysis}

The results of the post sequencing analysis are shown in Supplementary Table 1. In detail, $96.2 \%(175 / 182)$ of the samples were unambiguously identified at species level by means of the elective target alone $(92.4 \%, 168 / 182)$ or through the application of a multi-target approach $(3.8 \% 7 / 182)$. The remaining $3.8 \%$ of the products ( 2 redfish, and 2 pharaoh cuttlefish products, 2 Chilean and 1 blue mussel) was only identified at genus level, despite the use of 2 targets (COI and 16S rRNA). Overall, 33 (30 fish and 3 cephalopod products) out of the 182 products analyzed $(18.1 \%)$ were found to be non-compliant to the commercial designation and scientific denomination provided by the suppliers. The highest noncompliance rate was highlighted in the grouper group $(58.8 \%-10 / 17)$ in flatfish $(18.7 \%-3 / 16)$ and the cod/hake $(16.1 \%$ 9/56). The replacement of Atlantic cod with haddock (Melanogrammus aeglefinus) was the most frequently accounted. Notably, despite the high number of tuna products sampled in the study only two non-compliances, represented by the substitution of Thunnus albacares with Thunnus obesus or vice versa, were highlighted (Supplementary Table 1; Figure 3). Occasional substitution cases observed in less frequently sampled fish groups and mollusk category are detailed in Supplementary Table 1.

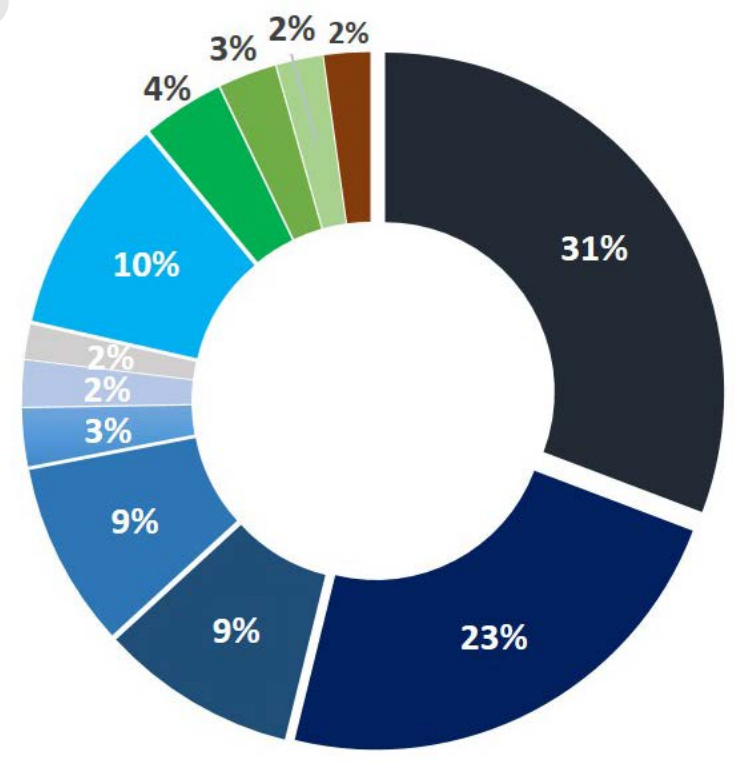

- cod/hake fish
- tuna
n grouper
n flatfish
goatfish
salmonidae
clupeidae
other fish
squid
cuttlefish
octopus
m.bivalves

Figure 2. Circle chart of the samples conferred by FBOs as result of their periodic selfchecking activity grouped per seafood category. 


\section{Discussions}

Up to a few decades ago, food companies used to select suppliers on the basis of their cost and location. As international government and industry put a stronger emphasis on food safety and quality, evaluating the right supplier has become a critical business decision. Companies are required to check the overall food safety status of their suppliers and highlight eventual significant compliance or quality system failures that could affect the production of topquality foods (https://webapps. traqtion. com/traqtionportal/servlet/PDFServlet?filename $=$ Costco_Food_Safety_Expectations. pdf; Barach, 2016). Although the suppliers' selection process is complex and onerous, especially for small companies, it may help to increase the brand reputation and drive the customers' demand (Beil, 2009). To cope with the several cases of fraud, food companies have begun to adopt the Vulnerability Assessment and Critical Control Points (VACCP) system, specifically aimed to prevent or detect illicit practices (Cavin et al., 2016; Spink et al., 2016). The VACCP system aims at identifying and monitoring vulnerability areas to detect, control and prevent fraudulent practices that could damage their business (Cavin et al., 2016; Spink et al., 2016). It follows that when a raw material is at risk of adulteration or replacement, the company must implement adequate verification systems to minimize the risk (Manning \& Soon, 2016). One of the most efficient and effective measures to verify the authenticity of the products relies on specific laboratory analyses.

The species identification protocol developed in our lab was specifically thought to be applied to both fresh and processed products belonging to different seafood categories, taking into consideration the supplier needs in terms of procedure reliability, cost and time sustainability. Therefore, considering that the specific features of each sample bring differences at various protocol steps (primers coverage, PCR amplification efficiency, level of DNA degradation, availability of reference sequences on the official database), a decision tree was developed to follow the most appropriate analytical pathway. The FLB COI barcode was selected as first choice and, for maximizing the amplification efficiency, the primer pairs were selected according to the seafood category (fish or mollusks). In the case of Thunnus spp., for which the COI gene doesn't exhibit sufficient variability within species (Wong and Hanner, 2008; Lowenstein et al., 2009), the analysis relied on the $c y t b$ gene. In addition, the $c y t b$ and the $16 S$ rRNA were also used as

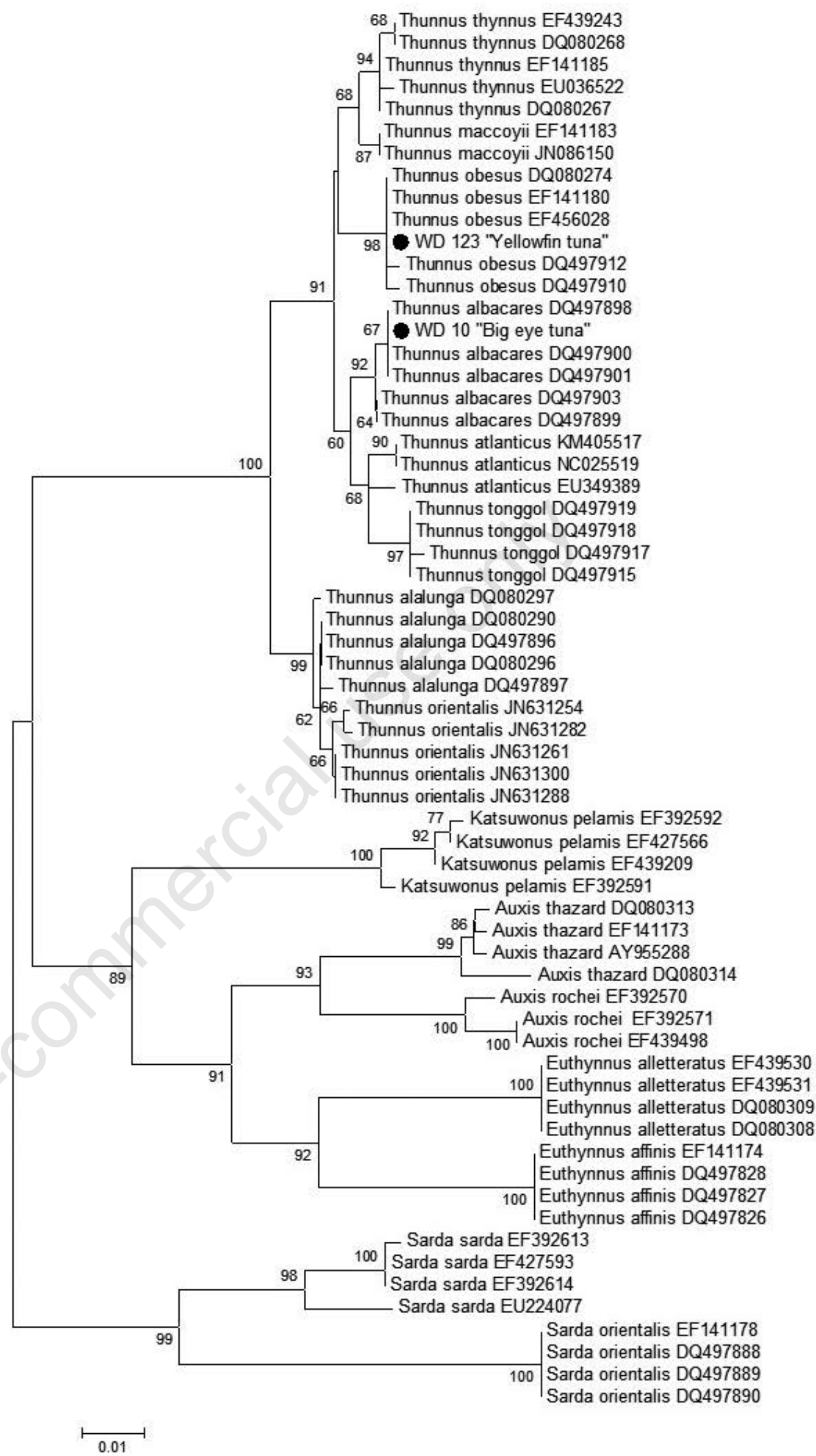

Figure 3. Distance tree inferred using the Neighbor-Joining method for the analysis of COI target sequences obtained from vouchered sequences of Thunnus sp, Auxis thazard, Auxis rochei, Katsuwonus pelamis, Sarda sarda, Sarda orientalis, Euthynnus alletteratus, Euthynnus affinis. The distance analysis was computed using the kimura 2-parameters model involving a total of 61 reference sequences. Bootstrap values $(\mathrm{BP})>70 \%$ obtained from 1000 replicates are shown below the branches. The analysis was performed MEGA 6.06. The sequences related to the two commercial samples are highlighted with $(\bullet)$. 
supportive markers of the COI if the identity values did not reach $98 \%$. The preliminary evaluation of DNA integrity in case of processed products and the application of two mini-barcode protocols for which the species resolution efficiency had already been proven (Armani et al., 2015) were considered in the decision tree to overcome issue related to DNA degradation. Moreover, the possibility to use a 5 '-exonuclease deficient Taq polymerase, specifically verified for amplification performance in presence of several inhibitors (Schrader et al., 2012), represents an option to improve the PCR reaction efficiency in presence of contaminated DNA (as for example those extracted from for mollusk bivalves). All the samples were amplified using the amplification protocol specifically selected according to our decision tree.

About the post sequencing analysis, $92.4 \%$ of the FBOs' samples were effectively identified by means of the elective target alone (COI or cytb for the tuna products). The introduction of a supporting target to the COI gene analysis at the end of the decisional chart offered a decisive improvement of the species disambiguation for a further $3.8 \%$ of the analyzed samples and allowed to reach a final overall identification rate of $96.4 \%$. (Table 1) Major limits to the successful species identification were recollected to the low resolution of the molecular target or to the absence of reference sequences.

Particularly, the lack of reference sequences prevented the species discrimination in cephalopod products and confirmed the noticeable need, particularly within Sepiidae family, of databases updating (Wen et al., 2017). Nevertheless, the molecular results were generally found informative enough to state the sample's non-compliance to the label information.

The overall non-compliances rate (18.1\%), calculated over the two-year survey, was consistent with the mislabelling percentage highlighted at retail level in the US (Warner et al., 2013) (18\%) and in South Africa (Cawthorn et al., 2015) (19\%) in the same period. Interestingly, within the cephalopod category, a relative high noncompliance rate was highlighted (18.7\%) considering the low number of products analysed. This data suggests that the enlargement of the sampling could result in a rise of the non-compliance and mislabelling rates within the category, as evidenced in Guardone et al. (2017). As already assessed in previous studies (Warner et al. 2013; Di Pinto et al., 2013) most of the non-compliances $(61.3 \% 19 / 31)$ were found in samples belonging to the Order Gadiformes (Gadidae and
Merluccidae) and to the family Serranidae (sub family Epinephelinae). As in the study of Mariani et al., (2015) only 2 non-compliances were found among tuna samples. The non-compliances were recollected to deliberate substitution for economic gain purposes or lack of operators' training to species identification (Cawthorn et al., 2015). Significant deliberate substitution cases were highlighted in Atlantic cod, often replaced by haddock (Melanogrammus aeglefinus), and grouper, frequently substituted by low or no commercial value species such as Brotola or Doctorfish ( $B$. multibarbata and A. monroviae) and 1 Atlantic salmon which was identified as Chum Salmon (Oncorhynchus keta). All the findings confirmed the need of an effective monitoring of the species identity for these products to prevent economic speculation to the detriment of both consumers and suppliers involved in the fisheries chain (Stawitz et al., 2016). Conversely, the lack of the operators' training plausibly posed the basis of unintentional species substitution in hakes, porgies, amberjack, turbots, clupeids and flying squid products. In these cases, the misidentification generally involved two species belonging to the same genus or family and the substitution is favoured by the species' similar morphological features, habitat overlapping or incidental bycatch phenomena (Table 1). Unintentional substitutions, although generally less relevant in term of economic loss, poses serious concerns about fishery transparency and sustainability since they may involve species below precautionary levels, such as $M$. paradoxus (Helyar et al., 2014).

\section{Conclusions}

The implementation of a seafood traceability system is becoming a major issue for the different FBO's mainly due to the highly articulate flow from catch to customer purchase which is further complicated by the introduction of outsourcing to third-party countries of raw commodities processing before the reselling to the country of origin or on the international trade market (Costa Leal et al., 2015). In this context, the regular use of standard and cost-effective DNA based analytical methods may represent a great opportunity to improve the self-check programs within the internal traceability system, to achieve customers' satisfaction and protect the company's interests. Thus, the study confirmed the usefulness of our optimized protocol for seafood identification to support traceability systems.

\section{References}

Armani A, Guardone L, Castigliego L, D'Amico P, Messina A, Malandra R, Guidi A, 2015b. DNA and Mini-DNA barcoding for the identification of Porgies species (family Sparidae) of commercial interest on the international market. Food Control 50:589-96.

Armani A, Guardone L, La Castellana R, Gianfaldoni D, Guidi A, Castigliego L, 2015a. DNA barcoding reveals commercial and health issues in ethnic seafood sold on the Italian market. Food Control 55:206-14.

Armani A, Tinacci L, Lorenzetti R, Benvenuti A, Susini F, Gasperetti L, Ricci E, Guarducci M, Guidi A, 2017. Is raw better? A multiple DNA barcoding approach (full and mini) based on mitochondrial and nuclear markers reveals low rates of misdescription in sushi products sold on the Italian market. Food Control 79:126-33.

Armani A, Tinacci L, Xiong, X., Titarenko E, Guidi A, Castigliego L, 2014. Development of a simple and costeffective bead-milling method for DNA extraction from fish muscles. Food Anal Methods 4:946-55.

Aung MM, Chang YS, 2014. Traceability in a food supply chain: Safety and quality perspectives. Food Control 39:172-84.

Barach JT, 2016. FSMA and Food Safety Systems: Understanding and Implementing the Rules. John Wiley \& Sons. Ltd. First Edition. 2017

Beil D, 2009. Supplier Selection. Available from: http://www-personal.umich. edu/ dbeil/Supplier_Selection_BeilEORMS.pdf

Cavin C, Cottenet G, Blancpain C, Bessaire T, Frank N, Zbinden P, 2016. Food Adulteration: From Vulnerability Assessment to New Analytical Solutions. CHIMIA Int J Chem 70:32933.

Cawthorn DM, Duncan J, Kastern C, Francis J, Hoffman LC, 2015. Fish species substitution and misnaming in South Africa: an economic, safety and sustainability conundrum revisited. Food Chem 185:165-81.

D'Amico P, Armani A, Gianfaldoni D, Guidi, A, 2016. New provisions for the labelling of fishery and aquaculture products: Difficulties in the implementation of Regulation (EU) n. 1379/2013. Marine Policy 71:147-56.

Di Pinto A, Di Pinto P, Terio V, Bozzo G, Bonerba E, Ceci E, Tantillo, G, 2013. DNA barcoding for detecting market substitution in salted cod fillets and battered cod chunks. Food Chem 
$141: 1757-62$

European Parliament and Council of the European Union, 2013. Regulation (EU) N. 1379/2013 of the Parliament and Council of the European Union of 11 December 2013 on the common organisation of the markets in fishery and aquaculture products, amending Council Regulations (EC) No $1184 / 2006$ and (EC) No 1224/2009 and repealing Council Regulation (EC) No 104/2000 Regulation of the European Parliament and of the Council of 29 April 2004 laying down specific hygiene rules for on the hygiene of foodstuffs. In: Official Journal, L 354/1, 28/12/2013.

Folmer O, Black M, Hoeh W, Lutz R, Vrijenhoek R, 1994. DNA primers for amplification of mitochondrial cytochrome c oxidase subunit I from diverse metazoan invertebrates. Mol Marine Biol Biotechnol 3:294-9.

Griffiths AM, Sotelo CG, Mendes R, PérezMartín, R I, Schröder U, Shorten, M, Silva HA, Verrez-Bagnis V, Mariani S, 2014. Current methods for seafood authenticity testing in Europe: Is there a need for harmonisation? Food Control 45:95-100.

Guardone L, Tinacci L, Costanzo F, Azzarelli D, D'Amico P, Tasselli G, Magni A, Guidi A, Nucera D, Armani A, 2017. DNA barcoding as a tool for detecting mislabeling of fishery products imported from third countries: An official survey conducted at the Border Inspection Post of Livorno-Pisa (Italy). Food Control 80:204-16.

Handy SM, Deeds JR, Ivanova NV, Hebert PD, Hanner RH, Ormos A, 2011. A single-laboratory validated method for the generation of DNA barcodes for the identification of fish for regulatory compliance. J AOAC Int 94:201-10.

Helyar, SJ, Lloyd HAD, De Bruyn M, Leake J, Bennett N, Carvalho GR, 2014. Fish product mislabelling: failings of traceability in the production chain and implications for illegal, unreported and unregulated (IUU) fishing. PloS One 9;e98691.

Kocher TD, Thomas WK, Meyer A, Edwards SV, Pääbo S, Villablanca FX, Wilson AC, 1989. Dynamics of mitochondrial DNA evolution in animals: amplification and sequencing with conserved primers. Proc Natl Acad Sci 86:6196-200.

Leal MC, Pimentel T, Ricardo F, Rosa R, Calado R, 2015. Seafood traceability: current needs, available tools, and biotechnological challenges for origin certification. Trends Biotechnol 33;3316.

Lowenstein JH, Amato G, Kolokotronis SO, 2009. The real maccoyii: identifying tuna sushi with DNA barcodes-contrasting characteristic attributes and genetic distances. PLoS One 4; 7866.

Mariani S, Griffiths AM, Velasco A, Kappel

K, Jérôme M, Perez-Martin RI, Schröder U, Verrez-Bagnis V, Silva H, Vandamme SG, Boufana B, Mendes R, Shorten M, Smith C, Hankard E, Hook SA, Weymer AS, Gunning D, Sotelo $\mathrm{CG}, 2015$. Low mislabeling rates indicate marked improvements in European seafood market operations. Frontiers Ecol Environ 13:536-40.

Palumbi SR, 1996. Nucleic acids II: The polymerase chain reaction. Mol System 2:205e247.

Schrader C, Schielke A, Ellerbroek L, Johne R, 2012. PCR inhibitors-occurrence, properties and removal. J Appl Microbiol 113;1014-26.

Spink J, Moyer DC, Speier-Pero C, 2016.
Introducing the Food Fraud Initial Screening model (FFIS). Food Control 69;306-14.

SSAFE 2016. Food fraud vulnerability assessment. Think like a criminal to fight food fraud. Disponibile su http://www.pwc.com/gx/en/food-supply-integrity-services/publications/ food-fraud-vulnerability-assessment. pdf.

Stawitz CC, Siple MC, Munsch SH, Lee Q, Derby SAFS, 2016. Financial and Ecological Implications of Global Seafood Mislabeling. Conservation Letters

Stringer C, Simmons G, Rees G, 2011. Shifting post production patterns: exploring changes in New Zealand's seafood processing industry. N Z Geog 67;161-73.

Tamm EE, Schiller L, Hanner RH, 2016. Seafood Traceability and Consumer Choice. In Naaum M, Hanner RH. Seafood authenticity and Traceability a DNA based method. a DNA based perspective Elsevier Academic Press, UK, 2016.

Warner K, Timme W, Lowell B, Hirshfield M, 2013. Oceana study reveals seafood fraud nationwide. Available at http:// oceana.org/ reports/ oceana-studyreveals-seafood-fraud-nationwide.

Wen J, Tinacci L, Acutis PL, Riina MV, Xu Y, Zeng L, Ying X, Chen Z, Guardone L, Chen D, Sun Y, Zhao J, Guidi A, Armani A, 2017. An insight into the Chinese traditional seafood market: species characterization of cephalopod products by DNA barcoding and phylogenetic analysis using COI and 16SrRNA genes. Food Control 82;33342. 